\title{
Is there the Pareto principle in public library circulation? A case study of one public library in Taiwan
}

\author{
Yi-Ting Yang and Jiann-Cherng Shieh* \\ Graduate Institute of Library and Information Studies, \\ National Taiwan Normal University, \\ No.162, Sec. 1, Hoping East Rd., Da-an District, Taipei 10610, TAIWAN \\ E-mail: 80415001E@ntnu.edu.tw; *jcshieh@ntnu.edu.tw (corresponding author)
}

\begin{abstract}
The Pareto Principle, also known as the $80 / 20$ rule is currently an important and popular management rule applied to marketing and customer relationship management (CRM). The rule indicates that the vital few causes inputs or efforts bringing the most results, outputs, or rewards. Analyzing circulation data to understand the usage status of library collections can help libraries comprehend their patrons' behaviour. However, little research has been done to analyse circulation data of public libraries to reveal patrons' usage behaviours. This paper aimed to analyse the circulation data generated by a municipality public library in Taiwan to gauge if the Pareto Principle manifested in this context. Subsequently, using bibliomining analysis, this research further identified vital patrons and their characteristics, as well as book-borrowed distributions to help analyse patrons' book borrowing behaviour to improve the efficiency of library management and library marketing as well as CRM. The circulation data of the public library follows the Pareto Principle, approximating to the 80/20 rule. Findings showed that when the accumulative percentage of patron is 24.7 percent, the accumulative percentage of borrowed books is 75.3 percent. The vital few patrons borrow the majority of the collections. This paper is the first study to reveal that the Pareto Principle could be found in circulation data of a public library in Taiwan. It could help libraries identify vital patrons and major collections, and improve the efficiency of their management and marketing activities in future. For other types of libraries, it would be interesting for us to explore the existence of the Pareto Principle further.
\end{abstract}

Keywords: Pareto Principle; 80/20 Rule; Book loan behaviour; Public Libraries; Bibliomining. 
Yang, Y.T. \& Shieh, J.C.

\section{INTRODUCTION}

In recent years, the concept of the Pareto Principle has become a popular guideline or tool in multiple business areas and the social context. The $80 / 20$ rule indicates that there is an unbalanced relationship between causes and results or between efforts and rewards: specifically, it maintains that 80 percent of rewards usually come from 20 percent of efforts, and the other 80 percent of efforts only produce 20 percent of the results. Therefore, if one could recognize, focus on, and control the vital 20 percent of efforts, her or she would obtain greater profits or efficiency. Similarly, if one could reform the 80 percent of effort exerted in vain, he or she would decrease losses. Many natural phenomena have been shown empirically to exhibit such a distribution.

Can the Pareto Principle be applied in the library and information service context? In recent years, a great deal of research has analysed library data and uncovered a variety of trends, patterns, and relationships. Bibliomining, or data mining in libraries, is the application of data mining techniques to data produced from library services (Nicholson 2003; Nicholson 2006; Shieh 2009). By applying statistics, bibliometrics, or data mining tools, libraries can better understand usage patterns and rules, enabling library managers to make decisions to meet user needs based on those mining results (Arsenova 2013; Zhang and Wang 2013; Xiang and Hao 2014; Hajek and Stejskal 2017). However, quality decisions must be based on quality data. Data processing is an important step in the knowledge discovery process (Han, Pei and Kamber 2011; Pandey 2014; Bajpai and Metkewar 2016). Identifying vital data and reducing the data to be analysed can lead to huge decision-making payoffs. Identifying vital patrons and core collections would allow library managers to provide better services.

Examining checkout distributions of circulation data helps libraries understand user behaviours. Previous discussions of data mining applications in academic libraries have emphasized usage analysis (Siguenza-Guzman et al. 2015). There have been a number of studies that have investigated usage analysis of academic libraries (Ahmad, Brogan and Johnstone 2014; Ping 2015; Al-Daihani and Abrahams 2016; Wu, Hu and Wang 2017). Renaud et al. (2015) analysed data from a university library and revealed the distributions of check-out activities based on criteria such as user type, academic department, Library of Congress classification, material type and material life span. They also correlated the findings with student grade point averages. Goodall and Pattern (2011) analysed the usage data of electronic resources, book loans, and visits in an academic library and correlated these data points with academic achievement. However, previous studies have mostly neglected to analyse circulation data in public libraries. In comparison with academic libraries, public libraries provide services to a wide range of users. Before data mining and data analytics, 
segmenting these various users and collections would conduct meaningful results. At present research focusing on this issue is still uncommon.

This study aims to discern if there are vital few patrons who borrow most of the collection, and to identify the vital patrons and their characteristics and book-borrowed distributions. Specifically, the objective of this study is to analyse the circulation data of public libraries and to examine whether the phenomenon of Pareto Principle could be found. If the Pareto Principle as conceptualized for this study could, in fact, be used to study patron patterns, this rule can serve as a much needed tool for public libraries to target patrons and effectively market their services. In view of the objective outlined above, three research questions are posed:

(a) Does the phenomenon of Pareto Principle manifest in the circulation data of public libraries? What is the percentage breakdown?

(b) Applying the $80 / 20$ rule, what are the characteristics of the top 20 percent vital patrons?

(c) Applying the $80 / 20$ rule, what are the characteristics of the collections borrowed by the top 20 percent vital patrons?

\section{LITERATURE REVIEW}

The $80 / 20$ rule originated from the Pareto Principle, named after the Italian economist Vilfredo Pareto who identified a general imbalance in property allocation: most (80\%) wealth belongs to a few (20\%) people. This model of imbalance has been observed repeatedly (Koch 1998; Nash 2016). In 1941, management consultant Joseph M. Juran applied this principle to quality management issues. He believed the principle of "the vital few and the trivial many" was universal (Koch 1998). In the late 1940s, Juran named his notion of "the vital few and the trivial many" as Pareto Principle after the Italian economist. The $80 / 20$ rule is an extension of the Pareto Principle developed by Richard Koch based on a theoretical view of Pareto and Juran, which he publicized in "The 80/20 Rule Principle - The Secret of Achieving More with Less." Koch (1998) noted that few causes, inputs, or efforts could bring most results, outputs, or rewards. The $80 / 20$ rule indicates that there is always an imbalance between causes and results, between inputs and outputs, or between efforts and rewards. The relationship between 80 percent and 20 percent provides a credible point of this phenomenon of imbalance: generally, 80 percent of outputs come from 20 percent inputs; 80 percent of results come from 20 percent of causes; and 80 percent of achievements come from 20 percent of efforts. 
Yang, Y.T. \& Shieh, J.C.

Koch (1998) pointed out that the $80 / 20$ rule could be applied in either the business or social context and in various fields. For example In business, 80 percent of a company's profits come from 20 percent of its customers, 80 percent of revenues come from 20 percent of the products, and 80 percent of sales come from 20 percent of the sellers (Koch 1998; Kim, Singh and Winer 2017). In quality management, 80 percent of the problems come from 20 percent of the faults (Koch 1998). In computer science, most software takes 80 percent of the time to run 20 percent of the programs (Koch 1998; Yamashita et al. 2015). In society, 80 percent of the crimes are 20 percent of the crimes behaviours, and 20 percent of drivers cause 80 percent of traffic accidents (Koch 1998). The unbalanced relationship between efforts and rewards or causes and results makes delineating the vital few very important. A successful company uses less effort to achieve high profits. Companies may improve profitability by reducing outputs or unbalancing employee salaries. To achieve this goal, they must identify which employees, departments, or units produce the most profits and provide them more resources, because concentrating on the groups of customers and the specific markets that are profitable can substantially improve a company's bottom line, having insight into the vital few is an important issue. Several studies also have suggested the benefit of applying the 80/20 rule (Yamashita et al. 2015; Kim et al. 2017; Mesbahi, Rahmani and Hosseinzadeh 2017).

The study of the Pareto Principle in libraries was initialized by Trueswell (1969) who applied the $80 / 20$ rule to address the relationship between library collections and circulation numbers. Trueswell (1969) noted that about 20 percent of collections bring 80 percent of circulation numbers (Nash 2016). Hardesty (1981) traced the book acquisitions and circulations of a university for five years. He found that 30 percent of books accounted for 80 percent of circulation. In recent years, Singson and Hangsing $(2013 ; 2015)$ analysed usage patterns of electronic journals academic consortia. They found out that the user downloads for some publishers follow the $80 / 20$ rule. The few core journals were downloaded the most. Some research suggested the $80 / 20$ rule could be used to identify the core collections within libraries. Burrell (1985) investigated the circulation data of university libraries and public libraries and found between 43 to 58 percent of circulating collections are required to account for 80 percent of borrowings. He developed a theoretical model of library operations to help libraries identify their core collections. Nisonger (2008) examined the 80/20 rule in relation to the use of print serials, downloads from electronic databases, and journal citations, concluding that the $80 / 20$ rule is a valid method for determining core concepts in journal collection management. However, few previous studies have explored the distributions of circulation in public libraries. This study examines a circulation dataset from a public library in Taiwan and analyses usage patterns to understand the distributions of patrons and circulations. The purpose is to identify if there are vital patrons in public libraries. 
This study concerns with the marketing of libraries and thus mainly examines the Pareto Principle based on the patrons' viewpoint.

\section{MATERIALS AND METHOD}

A public library in Taiwan is chosen as the case setting; it is located in a developing city that has a large area and fast-growing population. There are approximately 30 districts in the city, each district owns at least one library branch. The main library is located in the same district with the city government, and there are more than 100 library branches and reading rooms over the whole city. Reading rooms are small branches with smaller scale, which can serve in various regions and touch different kinds of people.

There are four types of data used in this study and they come from the following dataset:

(a) Circulation data: This dataset contains more than 18 million transactions conducted over two years and includes patron ID, item ID, branch library name, and date of transaction. Transaction types include local-borrow transactions, inter-borrow transactions and reservations.

(b) Patron data: This dataset contains data about 460,000 patrons, including patron ID, patron type, name of patron's branch library, and patron gender and occupation.

(c) Item data: This dataset encompasses all lending items in the public library, including item ID, title, author, call number, material type, subject code, and the name of the branch library that houses the item.

(d) Location data: This dataset contains information about each branch library such as branch name and district.

To preserve data privacy, the data went through pre-processing before they were obtained and processed by the researchers. The data used for data mining were first processed with one-way hashing function by the library (the raw data owner) and then the subset data were provided for the study. Columns that may have identified someone by providing information such as patron names, addresses, or phone numbers were deleted. Furthermore, patron corresponding data and branch names had been translated into substituted codes by some one-way hash functions respectively (Schneier 2015).

This paper analyses public library data to determine if the $80 / 20$ phenomenon of Pareto Principle manifests in libraries, and then identifies the distributions of the patrons and circulations. The data processing procedures involve the following:

(a) Integrating circulation data: The local-borrow transactions, inter-borrow transactions, and reservation data are integtated into one table. 
(b) Ranking the patrons: The transactions for each patron ID are summed up and then ranked in the table by the number of transaction.

(c) Calculating the accumulative percentage: The accumulative total of patrons and the accumulative total of items are calculated; the accumulative percentage are calculated separately. The accumulative percentage of patrons is the patron percentage rank divided by the total number of patrons. The accumulative percentage of items is the percentage of the accumulative total of that item divided by total number of items.

(d) Examining the circulation data with the Pareto Principle: The datum where the accumulative percentage of patrons and the accumulative percentage of items is $100 \%$ is identified. In addition to the total data from the two years, the data for each year are examined separately to identify the percentage with the concept of Pareto Principle in each year.

(e) Analyzing the distributions of circulation data: After identifying the percentage, the concept of $80 / 20$ rule is used to further analyse the distributions of circulation. The analysis involves collections borrowed by the top 20 percent of active patrons and considers the features of these collections such as subject, and material type. The analysis also takes in the patrons who borrowed 80 percent of items in the leaderboard and considers the characteristics of these patrons such as gender, occupation, and districts.

The database system used in this study is Microsoft SQL Server 2014. The data mining and analysis tools used are Microsoft SQL Server Data Tools (SSDT) and Microsoft Excel 2016 respectively. The researchers adopted a PC workstation with Intel Core i7-7700 CPU, 16G memory and 1T SSD to support database system operation, data processing and analysis tasks.

\section{RESULTS AND DISCUSSIONS}

\section{The Pareto Principle}

The patrons are ranked according to the number of items they borrow and the following are calculated - the accumulative total of patrons, the accumulative total of items, the accumulative total percentage of patrons, and the accumulative total percentage of items. As shown in Table 1, when the accumulative percentage of patrons is 24.69 percent, the accumulative percentage of items is 75.31 percent. That the accumulative percentage of patrons and the accumulative percentage of items is 100 percent demonstrates that the circulation data of the public library follow the Pareto Principle approximating to 80/20 rule. In other words, the vital few patrons account for most of the borrowings. The data in which 
the accumulative percentage of patrons is 20 percent and the accumulative percentage of items is 80 percent are also shown in Table 1.

Table 1: Rank of Borrowing and Accumulative Percentage

\begin{tabular}{rrrrr}
\hline \hline Borrow Amount & $\begin{array}{r}\text { Accumulative } \\
\text { patrons }\end{array}$ & $\begin{array}{r}\text { Accumulative } \\
\text { items }\end{array}$ & $\begin{array}{r}\text { Accumulative } \\
\text { patrons(\%) }\end{array}$ & $\begin{array}{r}\text { Accumulative } \\
\text { items(\%) }\end{array}$ \\
\hline 3212 & 1 & 3212 & 0.000217507 & 0.017778698 \\
3159 & 2 & 6371 & 0.000435013 & 0.035264036 \\
3088 & 3 & 9459 & 0.00065252 & 0.052356383 \\
3030 & 4 & 12489 & 0.000870027 & 0.069127695 \\
2990 & 5 & 15479 & 0.001087533 & 0.085677604 \\
2973 & 6 & 18452 & 0.00130504 & 0.102133416 \\
$\approx$ & & & & \\
56 & 91950 & 12534661 & 19.99973899 & 69.38043286 \\
56 & 91951 & 12534717 & 19.9999565 & 69.38074283 \\
56 & 91952 & 12534773 & 20.00017401 & 69.38105279 \\
56 & 91953 & 12534829 & 20.00039151 & 69.38136275 \\
$\approx$ & & & & \\
44 & 113496 & 13606589 & 24.68613786 & 75.31364706 \\
44 & 113497 & 13606633 & 24.68635537 & 75.3138906 \\
44 & 113498 & 13606677 & 24.68657288 & 75.31413415 \\
44 & 113499 & 13606721 & 24.68679038 & 75.31437769 \\
$\approx$ & & & & \\
35 & 134910 & 14453189 & 29.34382586 & 79.99965129 \\
35 & 134911 & 14453224 & 29.34404336 & 79.99984502 \\
35 & 134912 & 14453259 & 29.34426087 & 80.00003875 \\
35 & 134913 & 14453294 & 29.34447838 & 80.00023247 \\
$\approx$ & & & & \\
\hline
\end{tabular}

This study also analyses the data for each year separately (Table 2). For the first year, when the accumulative percentage of patrons is 26.76 percent, the accumulative percentage of items is 73.24 percent, and the sum of these two percentages is 100 percent. For the second year, when the accumulative percentage of patrons is 26.17 percent, the accumulative percentage of items is 73.83 percent, and the sum of these two percentages is 100 percent. Although the percentage is a little different in each year, they can be explained by the $80 / 20$ rule. Overall, the findings indicate that the circulation data of public libraries adhere to the Pareto Principle.

In summary, the percentage following the $80 / 20$ rule for the two years examined is $75.3 / 24.7$. For the first year and the second year, the percentages are $73 / 27$ and $74 / 26$ separately. These findings indicate that a few patrons would borrow the most items in the public library. The application of $80 / 20$ rule to identify the vital few patrons can significantly improve organizational efficiency, and the public library managers would certainly benefit from embracing this approach. In doing so, they could not only improve utilization but also give vital patrons more proper services. 
Table 2: Rank of Borrowing and Accumulative Percentage of Each Year

\begin{tabular}{|c|c|c|c|c|c|c|c|c|c|}
\hline \multicolumn{5}{|c|}{ First Year } & \multicolumn{5}{|c|}{ Second Year } \\
\hline 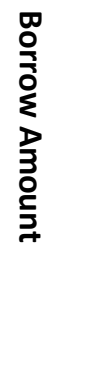 & 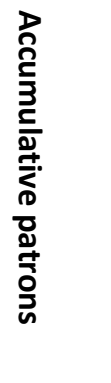 & 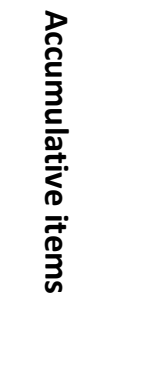 & 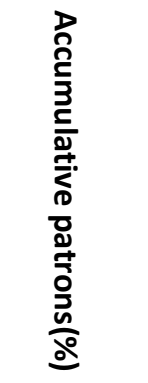 & 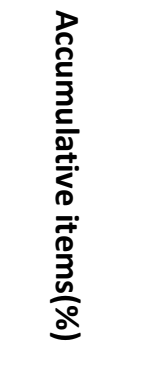 & 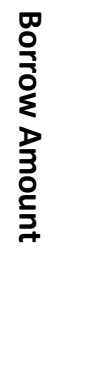 & 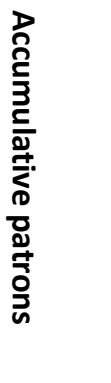 & 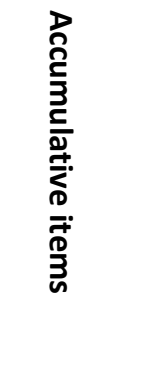 & 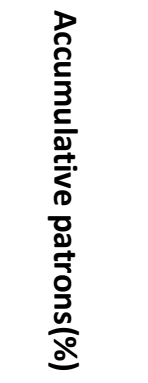 & 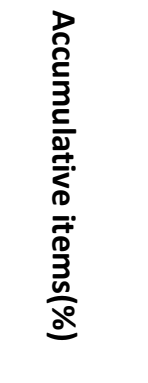 \\
\hline 3212 & 1 & 3212 & 0.000302 & 0.039732 & 2386 & 1 & 2386 & 0.000295 & 0.023902 \\
\hline 3159 & 2 & 6371 & 0.000605 & 0.078808 & 2048 & 2 & 4434 & 0.000591 & 0.044418 \\
\hline 3030 & 3 & 9401 & 0.000907 & 0.116288 & 1605 & 3 & 6039 & 0.000886 & 0.060497 \\
\hline 2973 & 4 & 12374 & 0.001209 & 0.153064 & 1346 & 4 & 7385 & 0.001182 & 0.073981 \\
\hline 2119 & 5 & 14493 & 0.001511 & 0.179275 & 1328 & 5 & 8713 & 0.001477 & 0.087284 \\
\hline 2013 & 6 & 16506 & 0.001814 & 0.204176 & 1328 & 6 & 10041 & 0.001773 & 0.100588 \\
\hline$\approx$ & & & & & $\approx$ & & & & \\
\hline 36 & 66166 & 5226147 & 19.99952 & 64.64627 & 43 & 67681 & 6588491 & 19.99953 & 66.00144 \\
\hline 36 & 66167 & 5226183 & 19.99982 & 64.64672 & 43 & 67682 & 6588534 & 19.99982 & 66.00187 \\
\hline 36 & 66168 & 5226219 & 20.00012 & 64.64716 & 43 & 67683 & 6588577 & 20.00012 & 66.0023 \\
\hline 36 & 66169 & 5226255 & 20.00042 & 64.64761 & 43 & 67684 & 6588620 & 20.00041 & 66.00273 \\
\hline$\approx$ & & & & & $\approx$ & & & & \\
\hline 27 & 88518 & 5921206 & 26.75569 & 73.244 & 32 & 88568 & 7369750 & 26.17157 & 73.82784 \\
\hline 27 & 88519 & 5921233 & 26.756 & 73.24433 & 32 & 88569 & 7369782 & 26.17187 & 73.82816 \\
\hline 27 & 88520 & 5921260 & 26.7563 & 73.24467 & 32 & 88570 & 7369814 & 26.17216 & 73.82848 \\
\hline 27 & 88521 & 5921287 & 26.7566 & 73.245 & 32 & 88571 & 7369846 & 26.17246 & 73.8288 \\
\hline$\approx$ & & & & & $\approx$ & & & & \\
\hline
\end{tabular}

\section{The Top 24.7 Percent Patrons}

\section{(a) Statistical Analysis of Patrons}

After establishing that public library data conform to the $80 / 20$ rule, the distributions of patrons are analysed to determine the characteristics of the top 20 percent active patrons and the features of the 80 percent collections they borrowed from. The two-year dataset for the Taiwan public library includes about 460,000 patrons who borrowed at least one item. Therefore, the top 24.7 percent is composed of about 115,000 patrons who borrowed at least 44 items. Applying the $80 / 20$ rule, these patrons are active users of the library. Identifying and understanding these patrons may help the library target users and market library services to them efficiently.

The characteristics of these top 24.7 percent of patrons are analysed. Table 3 presents the distributions of the top 24.7 percent of patrons by their birth year and gender. In general, 
most of the patrons were born in the 1970s, followed by the 2000s, and the percentage of female patrons is higher than that of males. Table 4 shows the results of the distributions of the top 24.7 percent of patrons by types and occupations. Most of the top patrons are general patrons, followed by families. By occupation, students borrow the most, followed by businesses and finance and then children. This is consistent with the findings in the next stage of analysis: families and children are vital patrons and children's books are also a popular material type. For public libraries, categorizing patrons is important because it enables them to develop collections for specific patrons, and recommend specific collections to targeted patrons.

Table 3: Distribution of Patrons' Birth Year and Gender

\begin{tabular}{rrrr}
\hline \hline Year of birth & Female & Male & Not identified \\
\hline \hline $2010 \mathrm{~s}$ & 1156 & 1126 & 19 \\
$2000 \mathrm{~s}$ & 12690 & 10544 & 67 \\
$1990 \mathrm{~s}$ & 7693 & 3713 & 23 \\
$1980 \mathrm{~s}$ & 10693 & 4254 & 131 \\
$1970 \mathrm{~s}$ & 24498 & 8749 & 334 \\
$1960 \mathrm{~s}$ & 12083 & 6748 & 88 \\
$1950 \mathrm{~s}$ & 3769 & 3424 & 17 \\
$1940 \mathrm{~s}$ & 873 & 1217 & 4 \\
$1930 \mathrm{~s}$ & 183 & 327 & 2 \\
$1920 \mathrm{~s}$ & 41 & 113 & 1 \\
$1910 \mathrm{~s}$ & 10 & 5 & 0 \\
Other & 82 & 47 & 3 \\
\hline \hline
\end{tabular}

Moreover, the top 24.7 percent patrons' percentage by patron type and gender among all patrons are analysed (Table 5). Except for general patrons, other types of patrons have percentages higher than 24.7 percent. Staff has the highest percentage (83\%) and VIP patrons (66\%) are also vital patrons. By gender, 25.5 percent female patrons and 24 percent male are vital patrons. Females have little higher percentage than the males. 
Yang, Y.T. \& Shieh, J.C.

Table 4: Distribution of Patrons' Occupation and Type

\begin{tabular}{lrrrrrr}
\hline \hline Occupation & VIP & General Volunteer & Family & Group & Staff \\
\hline \hline Agriculture & 2 & 424 & 1 & - & - & - \\
Arts & - & - & - & 1 & - & - \\
Business and Finance & 64 & 18366 & 66 & 52 & - & 11 \\
Children & 91 & 18009 & 1 & 1 & - & - \\
Education and Training & 31 & 4885 & 29 & 7 & 8 & 2 \\
Entertainment & - & 2 & - & - & - & - \\
Fishery & - & 3 & - & - & - & - \\
Freelance & - & 16 & - & 4 & - & 1 \\
General Services & 1 & 16 & - & 11 & - & 16 \\
Government & 23 & 5093 & 23 & 15 & 13 & 261 \\
Healthcare & - & 3 & - & 1 & - & - \\
Homemaker & - & 39 & - & 34 & - & - \\
Industrial & 28 & 7608 & 14 & 14 & 1 & 1 \\
Military & - & 87 & - & 1 & - & - \\
Others & 164 & 31263 & 449 & 186 & 20 & 110 \\
Animal agriculture & - & 1 & - & - & - & - \\
Religion & - & 2 & - & - & - & - \\
Student & 113 & 24905 & 30 & 10 & - & 9 \\
Transportation & - & - & - & 1 & - & - \\
Public Servant & - & 1 & - & - & - & - \\
Not identified & 1355 & 2 & 710 & 3 & 5 \\
\hline \hline
\end{tabular}

Table 5: Percentage of Patrons' Type and Gender.

\begin{tabular}{lrr}
\hline & Top 24.7\% Patrons & Percentage (\%) \\
\hline \hline Patron Type & & \\
VIP Patron & 525 & 66.28788 \\
General Patron & 112078 & 24.6394 \\
Volunteer & 615 & 50.49261 \\
Family & 1048 & 46.41275 \\
Group & 45 & 39.13043 \\
Staff & 416 & 83.36673 \\
\hline \hline Gender & & \\
Female & 73771 & 25.54866 \\
$\quad$ Male & 40267 & 24.03182 \\
$\quad$ Not identified & 689 & 36.63764 \\
\hline \hline
\end{tabular}




\section{(b) Bibliomining Analysis of Patrons}

To know the characteristics of these patrons, clustering of data mining techniques are applied to these 24.7 percent patrons. They are divided into four groups by K-means algorithm. Input variables are ages, occupations, and gender. The results are shown in Table 6. Patrons in Cluster 1 are $0-20$ years old, they are students or children, comprising 45 percent males and 55 percent females. Approximately 84 percent patrons in Cluster 2 are from 2132 years old; predominantly students and females. Patrons in Cluster 3 are highly females, mostly from 33-43 years old, and come from business and finance occupation sector. Patrons in Cluster 4 are mainly from 44-81 years old. They are are mainly from business and finance, as well as industries.

Table 6: Clusters of Patrons.

\begin{tabular}{|c|c|c|c|}
\hline Cluster & Variable & Value & Percentage \\
\hline \multirow[t]{5}{*}{ Cluster 1} & Patron Age & $0-20$ & $98.88 \%$ \\
\hline & Patron Gender & Female & $55.02 \%$ \\
\hline & & Male & $44.91 \%$ \\
\hline & Patron Occupation & Children & $64.13 \%$ \\
\hline & & Student & $35.23 \%$ \\
\hline \multirow[t]{12}{*}{ Cluster 2} & Patron Age & $0-20$ & $11.35 \%$ \\
\hline & & $21-32$ & $84.47 \%$ \\
\hline & & $33-43$ & $4.19 \%$ \\
\hline & Patron Gender & Female & $68.83 \%$ \\
\hline & & Male & $30.76 \%$ \\
\hline & Patron Occupation & Business and Finance & $9.00 \%$ \\
\hline & & Children & $2.43 \%$ \\
\hline & & Education and Training & $2.53 \%$ \\
\hline & & Government & $3.88 \%$ \\
\hline & & Industrial & $3.32 \%$ \\
\hline & & Others & $16.61 \%$ \\
\hline & & Student & $61.94 \%$ \\
\hline \multirow[t]{11}{*}{ Cluster 3} & Patron Age & $21-32$ & $15.01 \%$ \\
\hline & & $33-43$ & $84.99 \%$ \\
\hline & Patron Gender & Female & $73.46 \%$ \\
\hline & & Male & $25.44 \%$ \\
\hline & & Null & $1.10 \%$ \\
\hline & Patron Occupation & Business and Finance & $24.12 \%$ \\
\hline & & Education and Training & $6.66 \%$ \\
\hline & & Government & $5.69 \%$ \\
\hline & & Industrial & $8.60 \%$ \\
\hline & & Others & $36.11 \%$ \\
\hline & & Student & $18.21 \%$ \\
\hline \multirow[t]{13}{*}{ Cluster 4} & Patron Age & $0-20$ & $0.62 \%$ \\
\hline & & $21-32$ & $9.33 \%$ \\
\hline & & $33-43$ & $37.25 \%$ \\
\hline & & $44-81$ & $52.80 \%$ \\
\hline & Patron Gender & Female & $66.33 \%$ \\
\hline & & Male & $33.30 \%$ \\
\hline & Patron Occupation & Agriculture & $0.72 \%$ \\
\hline & & Business and Finance & $27.19 \%$ \\
\hline & & Education and Training & $7.99 \%$ \\
\hline & & Government & $8.43 \%$ \\
\hline & & Industrial & $10.40 \%$ \\
\hline & & Others & $41.75 \%$ \\
\hline & & Student & $3.38 \%$ \\
\hline
\end{tabular}


Yang, Y.T. \& Shieh, J.C.

The same clustering method was applied to all patrons who borrowed at least one item. The list of clustering results in Table 7 shows a great difference when compared with the previous results in Table 6 , indicating that using $20 / 80$ rule could point out the vital patrons.

Table 7: Clusters of All Patrons

\begin{tabular}{lllr}
\hline \hline Cluster & Variable & Value & Percentage \\
\hline \hline Cluster 1 & Patron Age & $0-19$ & $100.00 \%$ \\
& Patron Gender & Female & $53.85 \%$ \\
& & Male & $46.07 \%$ \\
& Patron Occupation & Children & $52.52 \%$ \\
& & Student & $47.08 \%$ \\
\hline Cluster 2 & Patron Age & $0-19$ & $100.00 \%$ \\
& Patron Gender & Female & $48.09 \%$ \\
& & Male & $51.85 \%$ \\
& Patron Occupation & Children & $98.57 \%$ \\
& & Student & $0.82 \%$ \\
\hline Cluster 3 & Patron Age & $0-19$ & $74.08 \%$ \\
& & $20-30$ & $25.92 \%$ \\
& Patron Gender & Female & $63.23 \%$ \\
& & Male & $36.70 \%$ \\
& Patron Occupation & Children & $15.10 \%$ \\
& & Others & $0.96 \%$ \\
& & Student & $82.91 \%$ \\
\hline Cluster 4 & Patron Age & $0-19$ & $3.24 \%$ \\
& & $20-30$ & $16.55 \%$ \\
& & $31-41$ & $36.10 \%$ \\
& & $42-78$ & $44.10 \%$ \\
& Patron Gender & Female & $65.17 \%$ \\
& & Male & $34.40 \%$ \\
& Patron Occupation & Business and Finance & $24.05 \%$ \\
& & Education and Training & $6.77 \%$ \\
& & Government & $7.77 \%$ \\
& & Industrial & $9.08 \%$ \\
& & Others & $37.30 \%$ \\
& & Student & $14.21 \%$ \\
\hline \hline
\end{tabular}

\section{The Collections Borrowed by the Vital Users}

\section{(a) Statistical Analysis of Collections Borrowed}

Finally, the features of 75.3 percent collections borrowed by the top $24.7 \%$ patrons was analysed. Table 8 shows the materials' types and subject codes in the New Classification Scheme for Chinese Libraries used for general collections. As expected, Chinese books are borrowed most frequently, followed by children's books and the CDs attached to items. In collections organised according to the New Classification Scheme for Chinese Libraries, items belonging to Linguistics and Literature (800) are borrowed most frequently, followed by Applied Sciences (400) and then Arts (900). 
Table 8. Distribution of Material Types and Subject Code in New Classification Scheme for Chinese Libraries*

\begin{tabular}{|c|c|c|c|c|c|c|c|c|c|c|}
\hline Materials type & 000 & 100 & 200 & 300 & 400 & 500 & 600 & 700 & 800 & 900 \\
\hline Chinese Book & 43020 & 353972 & 140993 & 242366 & 1239097 & 568368 & 82593 & 416972 & 3735515 & 322321 \\
\hline Foreign Reference & - & - & - & - & 4 & 2 & 2 & - & 30 & - \\
\hline Indonesian Book & 1 & 5 & 2 & - & - & 1 & 7 & 14 & 31 & 1 \\
\hline Audio Book & 298 & 4449 & 686 & 320 & 613 & 1285 & - & 61 & 4022 & 595 \\
\hline English Book & 109 & 376 & 130 & 287 & 68 & 98 & 223 & 791 & 10929 & 272 \\
\hline Foreign Child Book & 240 & 256 & 106 & 2233 & 607 & 5530 & 714 & 1079 & 87368 & 1109 \\
\hline Infant Book & 107 & 29 & - & 1605 & 3291 & 81781 & 5 & 24 & 32558 & 295 \\
\hline Child Book & 44093 & 38286 & 9240 & 407991 & 57602 & 221949 & 37738 & 152550 & 2744094 & 132242 \\
\hline Child Reference & 311 & - & - & 218 & 15 & 43 & 4 & 23 & 102 & 1 \\
\hline Child Picture Book & - & - & - & - & 7 & - & - & - & - & 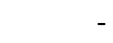 \\
\hline Attachment & 16724 & 5948 & 3010 & 65333 & 50334 & 43420 & 5902 & 12690 & 335886 & 35293 \\
\hline Teeanger Book & - & - & - & - & - & - & - & 1 & 136 & . \\
\hline Goverment Publication & - & - & - & 11 & 116 & 149 & 2 & 43 & 24 & 37 \\
\hline Music & 4 & 25 & 65 & - & 12 & 65 & - & - & 2926 & 4443 \\
\hline Aboriginal Book & - & - & - & - & - & 2 & - & - & - & 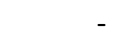 \\
\hline Book Box & - & - & - & - & - & - & - & - & 95 & 1 \\
\hline Thai Book & - & - & - & - & - & 1 & - & - & 4 & - \\
\hline Malay Book & 2 & - & - & - & - & - & 2 & - & - & - \\
\hline Reference Book & 31 & 1 & 14 & 220 & 69 & 109 & 13 & 97 & 95 & 53 \\
\hline Periodical & 51530 & 737 & 535 & 10324 & 39142 & 25130 & 63 & 1377 & 16835 & 8957 \\
\hline Video & 713 & 995 & 618 & 12136 & 5300 & 7021 & 2038 & 8646 & 7172 & 353248 \\
\hline Vietnam Book & - & 4 & - & - & - & - & 133 & 3 & 47 & 10 \\
\hline $\begin{array}{l}\text { Local Government } \\
\text { Literature }\end{array}$ & 3 & - & - & 5 & 2 & 6 & 4 & 21 & 1 & 4 \\
\hline E-resources & - & - & - & - & - & - & - & - & 4 & 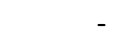 \\
\hline Comic Book & 2 & 307 & 225 & 635 & 527 & 538 & 176 & 573 & 4469 & 449478 \\
\hline Elderly Book & - & - & - & - & - & - & - & 12 & 5 & - \\
\hline Journal & - & - & 10 & - & 10 & 1 & - & - & - & - \\
\hline Korean Book & - & - & - & 3 & 1 & - & - & - & - & 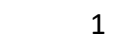 \\
\hline
\end{tabular}

*000 Generalities; 100 Philosophy; 200 Religion; 300 Science; 400 Applied Sciences;

500 Social Sciences; 600 History; 700 Geography; 800 Linguistics and Literature; 900 Arts.

In the second layer classification of items that had been borrowed by vital patrons, items belonging to Various Chinese literature (850) are borrowed most frequently, followed by Western literature (870) and then Oriental literature (860). Table 9 shows the distributions of popular items in the second layer classification. In the third layer classification, items borrowed more than 100,000 times belong to Fiction (857), Chinese Children literature (859), Japanese literature (861), and American literature (874). Table 10 shows the top 30 in the third layer classification and the number of items borrowed. 
Yang, Y.T. \& Shieh, J.C.

Table 9: Distribution of the Second Layer in New Classification Scheme for Chinese Libraries

\begin{tabular}{|c|c|c|c|c|c|c|c|c|c|}
\hline 000 & Items & 200 & Items & 400 & Items & 600 & Items & 800 & Items \\
\hline 000 & 1034 & 200 & 1451 & 400 & 4024 & 600 & 2155 & 800 & 513959 \\
\hline 010 & 24583 & 210 & 8002 & 410 & 354624 & 610 & 39812 & 810 & 108177 \\
\hline 020 & 3650 & 220 & 52107 & 420 & 659441 & 620 & 41626 & 820 & 7048 \\
\hline 030 & 1558 & 230 & 956 & 430 & 74932 & 630 & 3225 & 830 & 24052 \\
\hline 040 & 32984 & 240 & 13626 & 440 & 59227 & 640 & 299 & 840 & 7249 \\
\hline 050 & 55580 & 250 & 416 & 450 & 653 & 650 & 240 & 850 & 3509721 \\
\hline 060 & 3896 & 260 & 758 & 460 & 22872 & 660 & 1153 & 860 & 1079394 \\
\hline 070 & 8153 & 270 & 8502 & 470 & 14286 & 670 & 30293 & 870 & 1505767 \\
\hline 080 & 25382 & 280 & 6003 & 480 & 30237 & 680 & 2444 & 880 & 167646 \\
\hline 090 & 209 & 290 & 63625 & 490 & 175927 & 690 & 7794 & 890 & 1719 \\
\hline 100 & Items & 300 & Items & 500 & Items & 700 & Items & 900 & Items \\
\hline 100 & 2614 & 300 & 253520 & 500 & 6347 & 700 & - & 900 & 22963 \\
\hline 110 & 587 & 310 & 227258 & 510 & 3455 & 710 & 79355 & 910 & 51115 \\
\hline 120 & 26545 & 320 & 27959 & 520 & 481670 & 720 & 1997 & 920 & 13699 \\
\hline 130 & 1339 & 330 & 13952 & 530 & 45362 & 730 & 237834 & 930 & 2986 \\
\hline 140 & 5762 & 340 & 9745 & 540 & 100911 & 740 & 71948 & 940 & 618495 \\
\hline 150 & 1738 & 350 & 28825 & 550 & 64512 & 750 & 15981 & 950 & 47354 \\
\hline 160 & 630 & 360 & 30272 & 560 & 187592 & 760 & 14403 & 960 & 44995 \\
\hline 170 & 248746 & 370 & 14299 & 570 & 19393 & 770 & 12993 & 970 & 29489 \\
\hline 180 & 5619 & 380 & 109185 & 580 & 26303 & 780 & 148697 & 980 & 372912 \\
\hline 190 & 111469 & 390 & 26779 & 590 & 17938 & 790 & 10141 & 990 & 103609 \\
\hline
\end{tabular}

Table 10: The Top 30 Third Layer in New Classification Scheme for Chinese Libraries

\begin{tabular}{cccccc}
\hline Classification No. & \multicolumn{1}{c}{ Items } & Classification No. & Items & Classification No. & Items \\
\hline $\mathbf{8 5 7}$ & 1911334 & $\mathbf{5 2 3}$ & 270695 & $\mathbf{4 9 4}$ & 108243 \\
$\mathbf{8 5 9}$ & 1276528 & $\mathbf{8 5 5}$ & 268203 & $\mathbf{8 6 2}$ & 105689 \\
$\mathbf{8 6 1}$ & 921509 & $\mathbf{3 1 2}$ & 178680 & $\mathbf{7 3 3}$ & 96751 \\
$\mathbf{8 7 4}$ & 677247 & $\mathbf{5 6 3}$ & 160722 & $\mathbf{8 0 3}$ & 84554 \\
$\mathbf{9 4 7}$ & 577836 & $\mathbf{1 7 7}$ & 147883 & $\mathbf{7 3 1}$ & 81030 \\
$\mathbf{8 0 5}$ & 370272 & $\mathbf{5 2 8}$ & 142726 & $\mathbf{3 0 7}$ & 79950 \\
$\mathbf{4 2 7}$ & 337461 & $\mathbf{4 1 1}$ & 141158 & $\mathbf{8 1 5}$ & 78603 \\
$\mathbf{9 8 7}$ & 332690 & $\mathbf{8 7 6}$ & 131703 & $\mathbf{4 2 8}$ & 63625 \\
$\mathbf{8 7 3}$ & 313536 & $\mathbf{3 0 8}$ & 120121 & $\mathbf{1 9 2}$ & 63185 \\
$\mathbf{8 7 2}$ & 288577 & $\mathbf{4 2 6}$ & 109827 & $\mathbf{8 7 5}$ & 59440 \\
\hline \hline
\end{tabular}




\section{(b) Bibliomining Analysis of Collections Borrowed}

The association rules of data mining techniques were applied to the collections borrowed by 24.7 percent patrons, using the second classification number as bases to see the association patterns. Taking one association rule for example, " $820,690 \rightarrow 850$ " has the highest confidence, i.e. 0.996. That means, among the vital patrons who had borrowed books of classification number 820 (Chinese literature) and 690 (Chinese travels), 99.6 percent of them also borrowed books of classification number 850 (Various Chinese literature).

\section{CONCLUSION}

This paper examines the circulation data of a public library through the lens of the Pareto Principle, finding that the Pareto Principle does manifest in its circulation data. The findings indicate that, during the two-years covered by the investigation, 24.7 percent of the patrons borrowed 75.3 percent of all items borrowed. Conforming to the Pareto Principle, the majority of books-orrowing was done by the vital few patrons. The researchers analysed the distributions of the vital few patrons and the collections most frequently borrowed from. Among the vital few patrons, most of them are students, families, and children. Among the popular collections, the most frequently borrowed items are Chinese books and children's books. The most popular subject collection borrowed is Linguistics and Literature. This study also analysed these patrons and collections by data mining techniques. The findings of clustering have implications for public libraries to understand their patrons. Libraries could apply the Pareto Principle to identify vital patrons and collections and use that information to improve the efficiency of their library service, management and marketing.

Future research should analyse the correlation or connection between the vital few patrons and popular collections. Further studies exploring Pareto Principle based on the circulation data to identify popular items in public libraries could be conducted. The results of such an analysis would enable public librarians to make more effective management and marketing decisions, subsequently helping libraries improve utilization and patron satisfaction and develop collections that are more appealing to their patrons.

\section{ACKNOWLEDGEMENT}

This research received no specific grant from any funding agency in the public, commercial, or not-for profit sectors. 
Yang, Y.T. \& Shieh, J.C.

\section{REFERENCES}

Ahmad, P., Brogan, M. and Johnstone, M. N. 2014. The e-book power user in academic and research libraries: Deep log analysis and user customisation. Australian Academic \& Research Libraries, Vol.45, no.1: 35-47.

Al-Daihani, S. M. and Abrahams, A. 2016. A text mining analysis of academic libraries' tweets. The Journal of Academic Librarianship, Vol.42, no.2: 135-143.

Arsenova, I. 2013. New application of bibliometrics. Procedia-Social and Behavioral Sciences, Vol.73: 678-682.

Bajpai, J. and Metkewar, P. S. 2016. Data quality issues and current approaches to data cleaning process in data warehousing, Global Research and Development Journal for Engineering, Vol.1, no.10: 14-18.

Burrell, Q. L. 1985. The $80 / 20$ rule: Library lore or statistical law? Journal of Documentation, Vol.41, no.1: 24-39.

Goodall, D. and Pattern, D. 2011. Academic library non/low use and undergraduate student achievement: a preliminary report of research in progress, Library Management, Vol.32, no.3: 159-170.

Hajek, P. and Stejskal, J. 2017. Library usage mining in the context of alternative costs: the case of the municipal library of Prague. Library Hi Tech, Vol.35, no.4: 565-583.

Han, J., Kamber, M. and Pei, J. 2011. Data mining: Concepts and techniques. Waltham: Morgan Kaufmann.

Hardesty, L. 1981. Use of library materials at a small liberal arts college, Library Research, Vol.3, no.3: 261-282.

Kim, B. J., Singh, V. and Winer, R. S. 2017. The Pareto rule for frequently purchased packaged goods: an empirical generalization. Marketing Letters, Vol.28, no.4: 491-507.

Koch, R. 2011. The 80/20 principle: The secret of achieving more with less. New York: Currency Doubleday.

Mesbahi, M. R., Rahmani, A. M. and Hosseinzadeh, M. 2017. Highly reliable architecture using the $80 / 20$ rule in cloud computing datacenters. Future Generation Computer Systems, Vol.77: 77-86.

Nash, J. L. 2016. Richard Trueswell's Contribution to Collection Evaluation and Management: A Review, Evidence Based Library and Information Practice, Vol.11, no.3: 118-124.

Nicholson, S. 2003. The bibliomining process: Data warehousing and data mining for library decision making. Information Technology and Libraries, Vol.22n no.4: 146-151.

Nicholson, S. 2006. The basis for bibliomining: Frameworks for bringing together usagebased data mining and bibliometrics through data warehousing in digital library services, Information Processing \& Management, Vol. 42, no.3: 785-804.

Nisonger, T. E. 2008. The "80/20 rule" and core journals, The Serials Librarian, Vol.55, no.1- 
2: 62-84.

Pandey, R. K. 2014. Data Quality in Data warehouse: problems and solution. IOSR Journal of Computer Engineering, Vol.16, no.1: 18-24.

Ping, H. 2015. The Research on Personalized Recommendation Algorithm of Library Based on Big Data and Association Rules. Open Cybernetics \& Systemics Journal, Vol.9, no.1: 2554-2558.

Renaud, J., Britton, S., Wang, D. and Ogihara, M. 2015. Mining library and university data to understand library use patterns, The Electronic Library, Vol.33, no.3: 355-372.

Schneier B. 2015. Applied cryptography: Protocols, algorithms and source code in C, 20th Anniversary Edition. New York: John Wiley \& Sons.

Shieh, J. C. 2009. Bibliomining. Taipei: Mandarin Library \& Information Service.

Siguenza-Guzman, L., Saquicela, V., Avila-Ordóñez, E., Vandewalle, J. and Cattrysse, D. 2015. Literature review of data mining applications in academic libraries, The Journal of Academic Librarianship, Vol.41, no.4: 499-510.

Singson, M. and Hangsing, P. 2013. Reaffirming 80/20 rule in Indian Academic Consortia, Paper presented at the International Conference on Digital Libraries (ICDL) 2013: 464474. New Delhi,India.

Singson, M. and Hangsing, P. 2015. Implication of 80/20 rule in electronic journal usage of UGC-infonet consortia. The Journal of Academic Librarianship, Vol.41, no.2: 207-219.

Trueswell, R. L. 1969. Some Behavioral Patterns of Library Users: The 80/20 Rule. Wilson Libr Bull, Vol.43, no.5: 458-461.

Wu, F., Hu, Y. H. and Wang, P. R. 2017. Developing a novel recommender network-based ranking mechanism for library book acquisition. The Electronic Library, Vol.35, no.1: 5068.

Xiang, Z. and Hao, Z. 2014. Personalized requirements oriented data mining and implementation for college libraries. Computer Modelling \& New Technologies, Vol.18, no.2B: 293-300.

Yamashita, K., Mclntosh, S., Kamei, Y., Hassan, A. E. and Ubayashi, N. 2015. Revisiting the applicability of the pareto principle to core development teams in open source software projects. Proceedings of the 14th International Workshop on Principles of Software Evolution: 46-55. Bergamo, Italy.

Zhang, Q. S. and Wang, X. Y. 2013. Research of personalized information service based on association rules. Advanced Materials Research, Vol.760-762: 1800-1803. 